\title{
Paraplegia
}

\section{Benefits of Early Admission to an Organised Spinal Cord Injury Care System}

M. J. DeVivo, PH, P. L. Kartus, MPH, S. L. Stover, MD, P. R. Fine, PhD Department of Rehabilitation Medicine, University of Alabama at Birmingham, UAB Station, Birmingham, Alabama 35294 USA.

\begin{abstract}
Summary
Patients admitted to the University of Alabama Hospital between 1973 and 1985 were studied to determine the benefits, if any, of early admission to an organised, multidisciplinary spinal cord injury (SCI) care system. Patients admitted within 1 day of injury who received all subsequent care within the system were compared with patients who received their acute care services elsewhere and who were admitted to the system solely for rehabilitation. Both patient groups were comparable with respect to age, neurologic level and extent of spinal cord lesion, pre-existing major medical conditions, associated injuries, ventilator dependency and acute surgical procedure experience. Findings included statistically significant reductions in acute care and total lengths of stay coupled with a highly significant reduction in the incidence of pressure ulcers for patients admitted within 1 day of injury. Moreover, for patients admitted within 1 day of injury, mortality rates were lower than reported previously for patients not admitted to an organised SCI care system.
\end{abstract}

Key words: Spinal cord injury; Organised spinal cord injury care system; Length of stay; Hospital charges; Mortality; Medical complications.

Since 1970, 22 spinal cord injury (SCI) care systems have been designated by the National Institute on Disability and Rehabilitation Research and established throughout the United States. While the concept of co-ordinated care systems is laudable, an analysis of the impact of these systems is needed to document their efficacy. In an analysis of this kind, several fundamental questions should be addressed. For example, are patients admitted to SCI care systems 'better off'

This study was supported in part by Grant Number G008200053 from the National Institute on Disability and Rehabilitation Research, Department of Education, Washington, D.C., USA. Read at the 62nd Annual Meeting of the American Congress of Rehabilitation Medicine, Kansas City, Missouri, October 3, 1985. 
than patients admitted elsewhere (i.e., are their morbidity and mortality rates lower, are their lengths of stay shorter, are their hospital charges lower, etc.)? If they are 'better off', then how soon after injury must patients be admitted to the system to incur these benefits? Moreover, are the benefits of system care the same for all patients, or do certain groups of patients (e.g., those patients with neurologically complete lesions, patients of younger ages, etc.) receive greater benefits?

Although the first of these questions is the most basic, methodologically it has been the most difficult, partly because collection of comparable data on patients treated in non-system hospitals and rehabilitation centres has been extremely difficult. Nonetheless, two such studies have been conducted (Keith et al., 1986; Heinemann et al., 1986). One of these (Keith et al., 1986) compared a freestanding facility with the SCI care systems and found no difference in patient outcomes. However, the particular freestanding facility used in that study had many of the same characteristics and programs as the SCI care systems. Therefore, the similarity of patient outcomes was not surprising.

The second study compared post-rehabilitation functional status achieved by patients who were treated in a single SCI care system acute care unit with that achieved by patients who received their acute care elsewhere (Heinemann et al., 1986). All patients in both groups received comprehensive rehabilitation at the SCI care system. In general, system patients were found to have reduced acute care lengths of stay and greater functional ability at discharge from rehabilitation.

Other investigators have simply assumed that patients treated at these coordinated systems of care are indeed 'better off' and instead concentrated on comparing important differences between early and delayed admissions to organised, multidisciplinary systems, and within that context, examining various patient subgroups (Adkins et al., 1987; Apple et al., 1987; Charles et al., 1974, 1978; Donovan et al., 1984; Hamilton et al., 1976; Young, 1978). Unfortunately, the results of these studies are difficult to compare because early admission is defined differently in each case. For example, Hamilton et al. (1976) and Adkins et al. (1987) compared patients admitted to a system within 72 hours of injury with patients admitted to a system more than 72 hours post-injury, while Charles et al. $(1974,1978)$ utilised a 30 day post-injury criterion for early admission to a system. However, using 7 day intervals, Apple et al. (1987) concluded that the critical time for admission to the system was between 14 and 21 days post-injury. Moreover, in yet another study of pooled data from 11 SCI care systems conducted by Young (1978), each system used its own definition of early admission. To complicate matters further, studies involving aggregate data from more than one SCI care system (Donovan et al., 1984; Young, 1978) are somewhat difficult to interpret because the programs offered at each system are not identical.

Perhaps most importantly, in previous investigations the comparability of early and delayed admission patients was not assessed. It is likely admission to a system was delayed for many patients because their medical condition was unstable due to multiple, severe associated injuries and/or subsequent unpreventable complications that precluded their early transfer. This may account, at least in part, for the protracted lengths of stay and higher hospital charges that have been documented for delayed admission patients (Adkins et al., 1987; Apple, 1987; Charles et al., 1974, 1978; Hamilton et al., 1976; Young, 1978). 
Unlike most previous investigations, our study addressed, at least in part, all three questions posed in the opening paragraph. Our premise was that when a patient was admitted to a non-system hospital, a decision was made relatively quickly either to transfer the patient to a system hospital as soon as he was stabilised, transfer for rehabilitation only, or provide all acute care and rehabilitation services at the non-system facility. Of course, this is not a random decision. It is undoubtedly related to the hospital's perceived ability to manage the patient, as well as the patient's ability to pay for hospital services. Nonetheless, if the premise of a quick decision is correct, then the benefits of receiving acute care within a system can be assessed by comparing patients admitted to the system within 24 hours of injury (early admission) with patients who both received all acute care outside the system and who were subsequently admitted to the system for rehabilitation only (delayed admission). In this way, acute care length of stay, hospital charges and medical complication rates for patients within and without the system could be compared. Total length of stay and hospital charges could also be examined to determine if reductions in hospital length of stay and charges observed during acute care were maintained throughout rehabilitation as well.

\section{Methods}

The retrospective review of medical records from 794 SCI patients injured between 1973 and 1985 who were treated at the University of Alabama at Birmingham Spinal Cord Injury Care System (UAB-SCICS) yielded a 315 patient subset who had been admitted to the UAB-SCICS within one day of injury. A second subset of 401 patients admitted to the UAB-SCICS for rehabilitation only was identified. The remaining subset of 78 patients was admitted to the UAB-SCICS for both acute care and rehabilitation. However, admission occurred more than 1 day postinjury. Therefore, these patients were not included in the study.

Fifteen patients whose data were incomplete ( 14 of whom were from the delayed admission group) were deleted from the study. In addition, 26 patients who died prior to completing rehabilitation and 14 patients who experienced complete neurologic recovery were considered separately. As a result, most analyses were based on the remaining 284 patients in the early admission group and 377 patients in the delayed admission group.

The data abstracted from each patient's medical records are reflected in Table I. Because patients were not randomly assigned to the early and delayed admission groups, it was necessary to assess the comparability of the groups. The appropriate form of chi-square or Student's-t was used to test the statistical significance of differences between the two groups for each variable measured at admission that appears in Table I as well as ventilator usage and surgical procedures during acute care. Once the comparability of the two groups with respect to these variables was ensured, the groups were stratified by neurologic level and extent of spinal cord lesion and examined for differences in average length of stay, hospital charges and the incidence of specific secondary medical complications during acute care.

Hospital charges were adjusted to May 1990 dollars using the Consumer Price Index for all items, for all urban wage earners and clerical workers. Use of the Consumer Price Index medical care component produced very similar results with calculated dollar figures being somewhat higher than those reflected herein. In 
Table I Demographic and relevant medical data abstracted from each patient's chart

\begin{tabular}{ll}
\hline At admission & During acute care \\
\hline Age & Ventilator Usage \\
Date & Length of Stay \\
Neurologic Level of Lesion & Hospital Charges \\
Neurologic Extent of Lesion & \\
Pre-existing Major Medical Conditions: & Medical Complications: \\
diabetes mellitus & pulmonary emboli \\
obesity & thrombophlebitis \\
anaemia & pneumonia \\
alcoholism & gastrointestinal haemorrhages \\
drug addiction & urinary tract calculi \\
ischaemic heart disease & pressure ulcers \\
urinary tract disorders & \\
arthritis & \\
scoliosis & \\
Associated Injuries: & \\
fractured bones & Operative Procedures: \\
amputations & laminectomies \\
traumatic pneumothorax and hemotherax & laparotomies \\
third degree burns & spinal fusions \\
coma & tracheotomies \\
internal organ injuries & halo traction \\
& internal fixation devices \\
\hline
\end{tabular}

addition, because the distribution of hospital charges was significantly skewed to the right by several patients whose charges were substantially above those of the remaining patients, it was necessary to transform the hospital charge data during the analysis. The purpose of transforming the data was to reduce the undue influence of those patients with unusually high charges on the reported average charges for each group. The effect of transforming the data was to lower the reported average charges for all groups and increase the likelihood that reported differences would be statistically significant because of the reduced variability of the transformed data.

Separate analyses were conducted using the square root, natural log and inverse of the hospital charge data. Based on overall performance (convergence of the mean, median and mode, and magnitude of convergence of skewness and kurtosis co-efficients toward zero), the square root transformation provided the most nearly normal distribution of hospital charges, and was therefore selected for use in this study.

Since it was not possible to ascertain the exact number of patients who died at other hospitals prior to their planned admission to the UAB-SCICS, the acute care mortality rate of delayed admission patients could not be determined. Therefore, the mortality rate for early admission patients was compared with previously reported findings from two other frequently cited studies of patients who, in general, were not treated at organised, comprehensive multidisciplinary systems of care (Griffin et al., 1985; Kraus et al., 1979).

\section{Results}

Our first task was to assess the comparability of early and delayed admission 
patients to ensure that potential differences in their outcomes were not due to differences in injury severity. Overall, no statistically significant differences were observed between the early and delayed admission groups for year of injury, the associated injuries and pre-existing major medical conditions appearing in Table I, neurologic level and extent of spinal cord lesion at admission to the system or use of mechanical ventilators during acute care $(p>0.05)$. Although a slightly higher proportion of patients in the early admission group had spinal fusions (41\% vs. $33 \%, \mathrm{p}=0.029)$ and halo traction $(31 \%$ vs. $19 \%, \mathrm{p}<0.001)$, no statistically significant differences for any of the remaining operative procedures were observed. Early admission patients were also slightly younger $(\overline{\mathrm{x}}=29.5$ years $)$ than their delayed admission counterparts $(\overline{\mathrm{x}}=32.0$ years $)(\mathrm{p}=0.027)$. Although the small age difference should not bias the comparison of lengths of stay, hospital charges and risks of developing secondary medical complications between the early and delayed admission patients (DeVivo et al., 1990), the effect of the differences in spinal fusions and halo traction is unclear.

Closer inspection of the data revealed that neurologically complete quadriplegics in the early and delayed admission groups were not as comparable as patients in the other neurologic categories. For example, neurologically complete quadriplegics in the early admission group were twice as likely to have lesions at the third cervical segment and almost three times less likely to have lesions at the sixth cervical segment than neurologically complete quadriplegics in the delayed admission group. Not surprisingly given the difference in neurologic level of lesion, early admission patients were also more likely to require mechanical ventilators during acute care $(42 \%$ vs. $27 \%, \mathrm{p}=0.06)$. As a result, the comparison of early and delayed admission neurologically complete quadriplegics is biased somewhat in favour of the delayed admission patients. Unfortunately, further subgrouping of the data to control this bias was not possible because of the small sample sizes that would have resulted.

\section{Length of stay}

Average lengths of stay for both groups by neurologic level and extent of spinal

Table II Mean lengths of stay (days) for early and delayed admission patients by neurologic category

\begin{tabular}{|c|c|c|c|c|}
\hline $\begin{array}{l}\text { Neurologic } \\
\text { category }\end{array}$ & $\begin{array}{c}\text { Treatment } \\
\text { phase }\end{array}$ & Early admission & Delayed admission & $\mathrm{p}$ \\
\hline $\begin{array}{l}\text { Paraplegia, } \\
\text { Incomplete }\end{array}$ & $\begin{array}{l}\text { Acute Care } \\
\text { Rehabilitation } \\
\text { Total }\end{array}$ & $\begin{array}{l}22 \cdot 0 \\
46 \cdot 3 \\
68 \cdot 3\end{array}$ & $\begin{array}{l}30 \cdot 7 \\
50 \cdot 6 \\
81 \cdot 3\end{array}$ & $\begin{array}{l}0.0229 \\
0.3964 \\
0.0568\end{array}$ \\
\hline $\begin{array}{l}\text { Paraplegia, } \\
\text { Complete }\end{array}$ & $\begin{array}{l}\text { Acute Care } \\
\text { Rehabilitation } \\
\text { Total }\end{array}$ & $\begin{array}{l}19 \cdot 5 \\
62 \cdot 2 \\
81 \cdot 7\end{array}$ & $\begin{array}{l}32 \cdot 6 \\
62 \cdot 9 \\
95 \cdot 5\end{array}$ & $\begin{array}{r}<0.0001 \\
0.9041 \\
0.0169\end{array}$ \\
\hline $\begin{array}{l}\text { Quadriplegia, } \\
\text { Incomplete }\end{array}$ & $\begin{array}{l}\text { Acute Care } \\
\text { Rehabilitation } \\
\text { Total }\end{array}$ & $\begin{array}{l}19 \cdot 5 \\
59 \cdot 7 \\
79 \cdot 2\end{array}$ & $\begin{array}{r}36 \cdot 7 \\
71 \cdot 3 \\
108 \cdot 0\end{array}$ & $\begin{array}{r}<0.0001 \\
0.0631 \\
0.0001\end{array}$ \\
\hline $\begin{array}{l}\text { Quadriplegia, } \\
\text { Complete }\end{array}$ & $\begin{array}{l}\text { Acute Care } \\
\text { Rehabilitation } \\
\text { Total }\end{array}$ & $\begin{array}{r}31 \cdot 2 \\
90 \cdot 4 \\
121 \cdot 6\end{array}$ & $\begin{array}{r}38 \cdot 4 \\
83 \cdot 8 \\
122 \cdot 2\end{array}$ & $\begin{array}{l}0.0758 \\
0.3266 \\
0.9280\end{array}$ \\
\hline
\end{tabular}


cord lesion appear in Table II. Early admission patients in each neurologic category had substantially shorter acute care lengths of stay than their delayed admission counterparts (Fig. 1). Moreover, total lengths of stay were significantly reduced for all early admission patients except neurologically complete quadriplegics, for whom no statistically significant difference was observed due to the increased injury severity levels for early admission neurologically complete quadriplegics discussed previously (Fig. 2). Overall, these findings are consistent with those of other model SCI care systems (Gibson, 1990).

\section{Hospital charges}

Average hospital charges for both groups by neurologic level and extent of spinal cord lesion appear in Table III. Because the square root transformation was used to normalise skewed data, the sums of average hospital charges for acute care and rehabilitation do not equal average total hospital charges.

It is of more than casual interest that reduced lengths of stay observed in early admission patients (Table II) did not always result in significant dollar savings. Acute care hospital charges for early admission patients were significantly lower for those who were neurologically complete paraplegics and neurologically incomplete quadriplegics. Rehabilitation charges for early admission patients were significantly

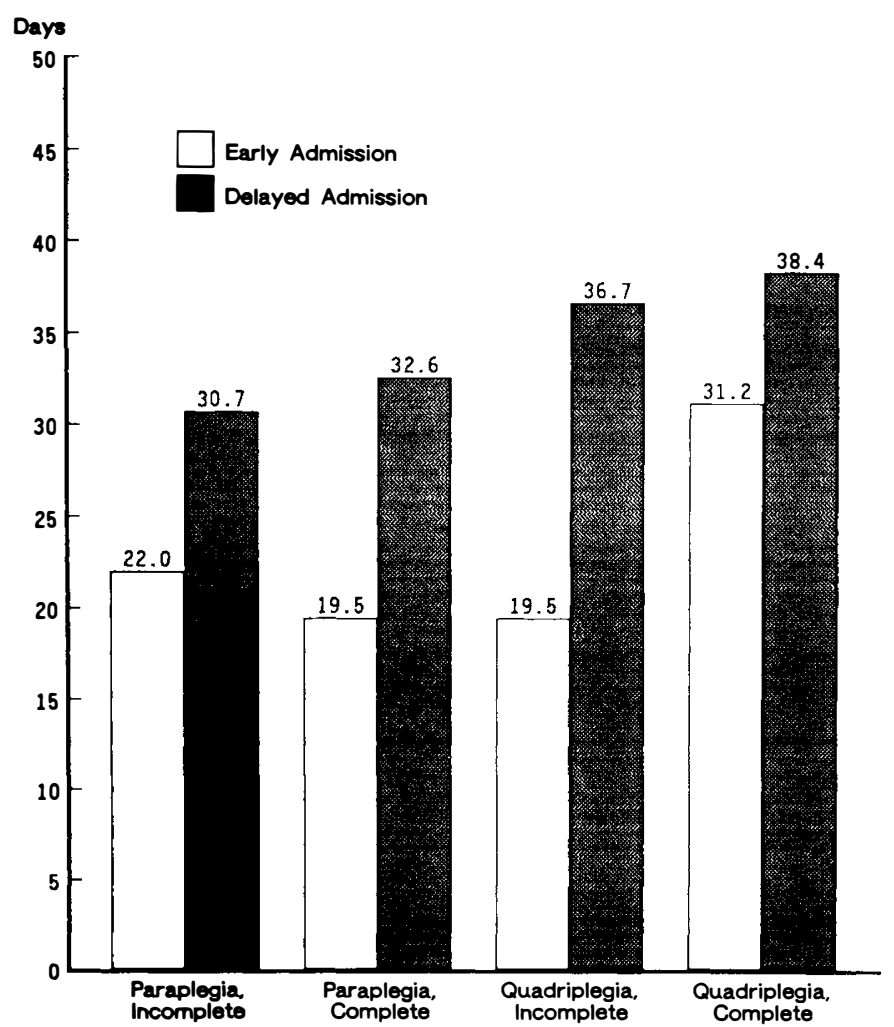

Figure 1 Mean acute care length of stay (days) for early and delayed admission patients by neurologic category. 


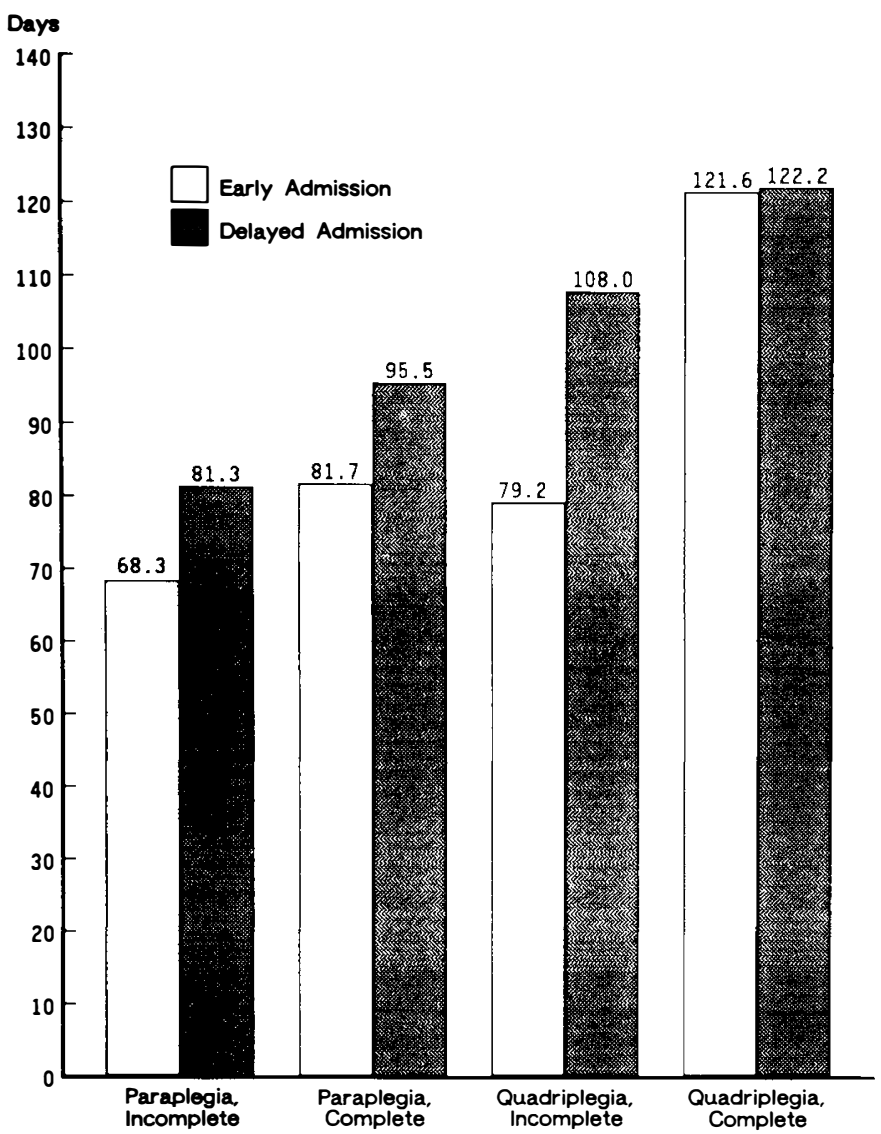

Figure 2 Mean total length of stay (days) for early and delayed admission patients by neurologic category.

Table III Mean hospital charges ${ }^{\star}$ for early and delayed admission patients by neurologic category

\begin{tabular}{|c|c|c|c|c|}
\hline $\begin{array}{l}\text { Neurologic } \\
\text { category }\end{array}$ & $\begin{array}{c}\text { Treatment } \\
\text { phase }\end{array}$ & Early admission & Delayed admission & $\mathrm{p}$ \\
\hline $\begin{array}{l}\text { Paraplegia, } \\
\text { Incomplete }\end{array}$ & $\begin{array}{l}\text { Acute Care } \\
\text { Rehabilitation } \\
\text { Total }\end{array}$ & $\begin{array}{r}\$ 16,473 \\
19,238 \\
37,306\end{array}$ & $\begin{array}{r}\$ 19,303 \\
23,553 \\
44,442\end{array}$ & $\begin{array}{l}0 \cdot 2564 \\
0.0343 \\
0.0607\end{array}$ \\
\hline $\begin{array}{l}\text { Paraplegia, } \\
\text { Complete }\end{array}$ & $\begin{array}{l}\text { Acute Care } \\
\text { Rehabilitation } \\
\text { Total }\end{array}$ & $\begin{array}{l}14,682 \\
27,809 \\
44,000\end{array}$ & $\begin{array}{l}18,979 \\
25,091 \\
46,226\end{array}$ & $\begin{array}{l}0.0270 \\
0.1524 \\
0.4777\end{array}$ \\
\hline $\begin{array}{l}\text { Quadriplegia, } \\
\text { Incomplete }\end{array}$ & $\begin{array}{l}\text { Acute Care } \\
\text { Rehabilitation } \\
\text { Total }\end{array}$ & $\begin{array}{l}13,412 \\
25,692 \\
41,033\end{array}$ & $\begin{array}{l}20,047 \\
31,346 \\
53,996\end{array}$ & $\begin{array}{l}0.0157 \\
0.0654 \\
0.0134\end{array}$ \\
\hline $\begin{array}{l}\text { Quadriplegia, } \\
\text { Complete }\end{array}$ & $\begin{array}{l}\text { Acute Care } \\
\text { Rehabilitation } \\
\text { Total }\end{array}$ & $\begin{array}{l}28,915 \\
46,491 \\
80,306\end{array}$ & $\begin{array}{l}23,629 \\
37,721 \\
63,351\end{array}$ & $\begin{array}{l}0 \cdot 2257 \\
0 \cdot 0162 \\
0.0099\end{array}$ \\
\hline
\end{tabular}

^Square root transformations-hospital charges adjusted to May, 1990 dollars 
lower for neurologically incomplete paraplegics, while rehabilitation dollar savings for early admission neurologically incomplete quadriplegics were of borderline statistical significance. Total hospital charges were significantly lower for early admission neurologically incomplete quadriplegics, while savings for early admission neurologically incomplete paraplegics were of borderline statistical significance.

Despite shorter acute care lengths of stay, acute care hospital charges for neurologically complete quadriplegics were higher for early admission patients. Rehabilitation and total hospital charges were also higher for neurologically complete quadriplegics in the early admission group. Because the UAB-SCICS is affiliated with a major regional medical centre in an urban area, its per diem costs (and consequently its charges) are higher than those in smaller community hospitals where many delayed admission patients received acute care services. Also, the differential in hospital charges for neurologically complete quadriplegics can be attributed, in large part, to differences in injury severity levels of early and delayed admission patients discussed previously.

\section{Medical complications}

There were no statistically significant differences in the incidence of most medical complications developing during acute care for early and delayed admission patients. Early admission patients were slightly less likely to develop pulmonary emboli ( $2 \%$ vs. $3 \%)$, gastrointestinal haemorrhages ( $2 \%$ vs. $4 \%$ ) and urinary tract calculi $(0 \%$ vs. $1 \%)$, but were slightly more likely to develop thrombophlebitis $(6 \%$ vs. $5 \%$ ) and pneumonia (15\% vs. $12 \%)$. There were, however, two statistically significant findings: early admission patients with neurologically incomplete spinal cord lesions were less likely to develop pulmonary emboli $(0 \cdot 7 \%$ vs. $5 \cdot 4 \%$, $\mathrm{p}=0.05)$, while early admission, neurologically complete quadriplegics were more likely to develop pneumonia $(37 \cdot 1 \%$ vs. $19 \cdot 1 \%, p=0.02)$, due once again, at least in part, to the higher lesion levels of neurologically complete quadriplegics in the early admission group.

Perhaps our most striking finding concerned the incidence of grade two or greater pressure ulcers developing during acute care (Table IV). These ulcers involve both the epidermal and dermal layers, extending into the adipose tissue or beyond. All delayed admission patients except neurologically incomplete paraplegics were much more likely to develop these more serious pressure ulcers than

Table IV Percentage of early and delayed admission patients developing grade two or greater pressure ulcers during acute care by neurologic category

\begin{tabular}{lccc}
\hline Neurologic & Early admission & Delayed admission & p \\
category & $4 \cdot 8$ & $5 \cdot 3$ & - \\
\hline Paraplegia, Incomplete & $10 \cdot 3$ & 26.6 & 0.8789 \\
Paraplegia, Complete & $2 \cdot 8$ & $25 \cdot 5$ & 0.0036 \\
Quadriplegia, Incomplete & $14 \cdot 5$ & $45 \cdot 6$ & $0 \cdot 0001$ \\
Quadriplegia, Complete & $8 \cdot 1$ & $25 \cdot 5$ & $0 \cdot 0001$ \\
All patients & & $<\cdot 0001$ \\
\hline
\end{tabular}


were their early admission counterparts. Moreover, there was a downward trend in the proportion of early admission patients who developed these pressure ulcers from $11 \cdot 1 \%$ for patients injured before 1978 to only $6 \cdot 4 \%$ for patients injured between 1983 and 1985. A comparable trend was not observed in the delayed admission patients. It is believed these findings explain, at least in part, the protracted acute care lengths of stay and associated hospital charges incurred by many delayed admission patients.

\section{Neurologic recovery}

While it was not possible to determine how many potential delayed admission patients experienced complete neurologic recovery prior to referral to the UABSCICS, this should be a very small number because one of the eligibility criteria for this study was that patients had to be injured severely enough to require rehabilitation. In fact, because of this criterion, no early admission patients who recovered during acute care were included in the study. However, as indicated previously, a total of 14 patients who required rehabilitation and were therefore included in the study did experience complete neurologic recovery by the end of the rehabilitation process. Interestingly, 10 of the 315 patients $(3.2 \%)$ in the early admission group experienced complete neurologic recovery, compared with only 4 of the 401 patients $(1.0 \%)$ in the delayed admission group $(p=0.08)$. Nonetheless, the potential bias towards slightly overestimating the difference in neurologic recovery rates between early and delayed admission patients should be considered when interpreting these data.

We recognise that complete neurologic recovery is a crude measure of overall neurologic recovery. Many patients in both the early and delayed admission groups undoubtedly experienced varying degrees of neurologic recovery. Unfortunately, motor index scores were usually not available in the medical records of patients who did not have their acute care at the UAB-SCICS.

\section{Mortality}

Fifteen patients in the early admission group (4.8\%) died during acute care, and an additional 5 patients $(1.6 \%)$ died during rehabilitation. While it was not possible to determine the number of potential delayed admission patients who died prior to referral to the UAB-SCICS, we did determine that 6 delayed admission patients $(1 \cdot 5 \%)$ died during rehabilitation at the UAB-SCICS.

Eleven of $315(3 \cdot 5 \%)$ early admission patients died within 28 days of injury. This statistic compares favourably with previous reports of acute care mortality. For example, 32 of $363(8.8 \%)$ patients injured in 1970 or 1971 and treated at hospitals in one of 18 northern California counties died within 28 days of injury ( $p<0.01$ when compared to UAB-SCICS) (Kraus et al., 1979). Similarly, 10 of 96 (10.4\%) patients injured prior to 1982 who were treated at hospitals in Olmsted County, Minnesota died within 28 days of injury $(p<0.02$ when compared to UABSCICS) (Griffin et al., 1985).

These differences can be explained, in part, by the different time periods, since acute survival rates have improved in recent years (DeVivo et al., 1990). However, 
it should also be noted that early admission patients treated at the UAB-SCICS were more severely injured than patients in these other studies in that they were considerably more likely to have neurologically complete lesions $(52 \%$ for UABSCICS, $30 \%$ for northern California and 35\% for Minnesota). There were no substantial differences in either the average age or neurologic level of lesion among the three study populations.

Overall, the finding of enhanced survival rates for early admission patients is consistent with the results of a recently published study comparing patients treated at other model SCI care systems with patients treated at non-system hospitals (DeVivo, 1990).

\section{Discussion}

To put the benefits of early admission to the system that we have described into an appropriate context, it is important to discuss, at least briefly, the nature of the acute care component of the UAB-SCICS. The UAB-SCICS has adopted a co-operative inter-departmental policy requiring joint evaluation and management of all acute SCI patients by specialists in trauma, neurosurgery, orthopaedic surgery, pulmonary medicine, urology and rehabilitation medicine. Acute care facilities available include a fully staffed Department of Emergency Medicine, the University Hospital Emergency Department, a trauma service, the Division of Pulmonary and Critical Care Medicine, a surgical intensive care unit, and a neurological intensive care unit. The latter is staffed by specially trained personnel with substantial experience managing neurologically impaired patients. Acute medical services are provided until the patient is ready for transfer to the system's rehabilitation facility. Nonetheless, involvement of rehabilitation-oriented personnel begins within the first 24 hours of the patient's initial admission to the system's acute care facility. This involvement continues after discharge from rehabilitation, in keeping with the system's lifetime continuum of care philosophy.

We have described some of the benefits of early admission to an organised multidisciplinary SCI care system. The current focus has been on those benefits related to the acute care phase of treatment. Rehabilitation and total length of stay as well as associated hospital charges were examined to ensure that initial benefits achieved during the acute care phase were maintained throughout the entire course of care (i.e., patients were not being transferred from the acute care setting to the rehabilitation facility before they were physically able to participate in the rehabilitation process).

Despite the unequivocal advantages of early admission that we have demonstrated, the benefits have been somewhat underestimated. For example, benefits for all neurologically complete quadriplegics were underestimated because the patients admitted within 1 day of injury were more likely to have a higher lesion level and require artificial ventilatory support. Moreover, medical records for early admission patients are often more complete than for delayed admission patients. Thus, the incidence of medical complications in the delayed admission group is probably not as well documented as in their early admission counterparts. Finally, further studies are needed to document the benefits of the organised multidisciplinary rehabilitation and long term follow-up programs that are an integral part of each system's lifetime continuum of care philosophy. 


\section{Conclusion}

These data support the contention that early admission to an organised multidisciplinary SCI care system will lead to reduced mortality, a slightly greater chance of neurologic recovery, shorter lengths of stay, lower hospital charges and a lower incidence of pressure ulcers.

\section{References}

AdKINS RH, Waters RL, WEISs MH et al. 1987 SCI care system evolution and the associated effects on acute medical complications and lenghts of stay. ASAI Abstracts Digest 13:92-93.

APPLE DF, AlBRight C, HuCKEBA J et al. 1987 The importance of early admission to a system of spinal cord injury care. ASIA Abstracts Digest 13:86-91.

Charles ED, Fine PR, Stover SL et al. 1978 The costs of spinal cord injury. Paraplegia 15:302-310.

Charles ED, VAN Matre JG, Miller JM 1974 Spinal cord injury-a cost benefit analysis of alternative treatment modals. Paraplegai 12:222-231.

DEVIvo MJ 1990 Life expectancy and causes of death for persons with spinal cord injuries. In: Spinal Cord Injury: The Model. Proceedings of the National Consensus Conference on Catastrophic Illness and Injury, December 1989. Atlanta, Georgia: The Georgia Regional SCI Care System, Shepherd Center for Treatment of Spinal Injuries, Inc., In Press.

DEVIVo MJ, KaRTUS PL, RUTT RD et al. 1990 The influence of age at time of spinal cord injury on rehabilitation outcome. Archives of Neurology 47:687-691.

DEVIvo MJ, RUTT RD, BLACK KJ et al. 1990 Comparison of rehabilitation outcomes for patients injured between 1973 and 1986. ASIA Abstracts Digest 16:4.

DONOVAN WH, CARTER RE, BEDBROOK GM et al. 1984 Incidence of medical complications in spinal cord injury: patients in specialised, compared with non-specialised centres. Paraplegia 22:282-290.

GiBSON CJ 1990 Criteria for evaluating performance of the system. In: Spinal Cord Injury: The Model. Proceedings of the National Consensus Conference on Catastrophic Illness and Injury, December 1989. Atlanta, Georgia: The Georgia Regional SCI Care System, Shepherd Center for Treatment of Spinal Injuries, Inc., In Press.

GRIFFIN MR, OPITZ JL, KURLAND LT et al. 1985 Traumatic spinal cord injury in Olmsted County, Minnesota, 1935-1981. American Fournal of Epidemiology 121:884-895.

Hamilton BB, RATh GJ, MEYER PR et al. 1976 A basic evaluation framework for spinal cord injury care systems. Paraplegia 14:87-94.

HeINEMANN AW, YARKONY GM, RoTh EJ et al. 1986 Functional outcome in spinal cord injury: a comparison of spinal cord center vs. general hospital care. Archives of Physical Medicine and Rehabilitation 67:636.

KeITH RA, ARONOW HU, MADORSKy JB et al. 1986 Comparison of outcomes from a free-standing facility with the regional spinal cord injury systems. Archives of Physical Medicine and Rehabilitation 67:636.

KRAUS JF, Franti CE, Borhani NO et al. 1979 Survival with an acute spinal cord injury. Fournal of Chronic Disease 32:269-283.

YouNG JS 1978 Initial hospitalization and rehabilitation costs of spinal cord injury. Orthopedic Clinics of North America 9:263-270. 